Journal of Engineering and Applied Sciences 14 (Special Issue 6): 9455-9466, 2019

ISSN: 1816-949X

(C) Medwell Journals, 2019

\title{
Condensation Polymerization of Anthocyanin Biomolecule and its Effect on Polymers
}

\author{
${ }^{1}$ Jaleel Kareem Ahmed, ${ }^{2}$ ZuhairJabbar Abdul Ameer and ${ }^{1}$ Shaden Abdullah Hamza \\ ${ }^{1}$ Department of Polymer and Petrochemical Industries, \\ College of Materials Engineering, University of Babylon, Iraq \\ ${ }^{2}$ Department of Prosthetics and Orthotics Engineering, \\ College of Engineering, University of Karbala, Iraq
}

\begin{abstract}
This study deals with pure Iraqi red beet juice which is extracted mechanically into two states, the pure anthocyanin juice and its solid state obtained by evaporation the pure anthocyanin juice until obtained the pure solid anthocyanin. By boiling the juice at $102^{\circ} \mathrm{C}$ and heating the solid at $110^{\circ} \mathrm{C}$ both of them show dimerization product which are confirmed from the weight of liberated water and the degree of polymerization is 2 (dimer formation). The pure solid anthocyanin and dimer anthocyanin (by heating and boiling) added to biopolymers (poly vinyl alcohol, poly methyl methacrylate, starch and cellulose)and noticed that this pigment effected on the glass transition temperature, density and hardness of biopolymers.
\end{abstract}

Keywords: Condensation polymerization, anthocyanin, biopolymers and poly methyl methacrylate

\section{INTRODUCTION}

Anthocyanin is Greek word means anthos-flower andkianos-blue and it used originally for describinga blue and red pigment, is the significant group in plant pigments which has high solubility in polar solvents and water (Miraje et al., 2015). Anthocyanin is an eminent color pigment which found in several vegetables, fruits and flowers giving a juice its purple hue (Alongi, 2010). It is kind of flavonoids that are phenolic compounds and have the C6-C3-C6 skeleton (Ferreiro-González et al., 2014). It was known as a functional material in human health and was used widely in medicine and food industries (Mei et al., 2014). The antioxidant activity is the most important function of anthocyanin which reduces a singlet oxygen) free radical) in the oxidation reactions of chelate metal and lipid with a wide extent of pharmacological, anti-allergenic, anti-microbial, anti-arteriogenic, anti-thombosis, anti-inflammatory properties, anticancer activity, anti-oedema properties, cardio-protection and vasodilator (Clemente and Galli, 2011). The free anthocyanins act as monomeric pigments which are unbounded to other sorts. The polymeric anthocyanins can be created in the processes of copigmentation and direct condensation. The pigments which formed have a chemical stability more than a free monomeric and the wine color was stabilizing by variation to the more brick red (Tsanova-Savova et al., 2002). More resistant for decoloration when anthocyanins are polymerized (Predrag et al., 2003). The changes in $\mathrm{pH}$ are not effecting on polymeric pigments. The polymerized anthocyanin was creating through storage and thermal processing in a temperature and time-dependent method which accelerated by the presence of light,oxygen, flavanol derivatives and ascorbic acid (Palencia, 2009). The polymer term was used to signify a particular class from macromolecules which consist from set of orderly repeated chemical units of a same kind or possibly from very limited number of various kinds, often only two, linked end to end or by more complex ways to form the chain molecule by polymerization process. In case of only one type from chemical unit the identical polymer is a homo-polymer, if there was more than one kind it is a copolymer (Bower, 2002). During development science of polymer, two categories were used. The first was based on composition of polymer, which divided polymers into addition and condensation polymers but the second category was based on a polymerization mechanism, which divided into chain and step polymerizations but these terms are usually used synonymously because generality condensation polymers were produced through step polymerizations and generality addition polymers were produced through chain polymerizations but this is notalways a case (Odian, 2004). Condensation polymers were obtained from a random reaction of two molecules can be monomer, oligomer or higher molecular weight average each having integral functional end units such as hydroxyl groups or carboxylic acid (Fried, 2014). The repeated units number in a separated polymer chain is named as a degree of polymerization, $\mathrm{x}_{\mathrm{n}}$ (Mitchell, 2004). The science of macromolecules was divided into biological and non-biological matters, which considered a large importance. Biological polymers have very institution in a life and intelligence and also provide much of a food on which human exits (Billmeyer, 1984). Polyvinyl alcoholas a hydrophilic polymer is

Corresponding Author: Jaleel Kareem Ahmed, Department of Polymer and Petrochemical Industries, College of Materials Engineering, University of Babylon, Iraq Tel: 07901815078 
water-soluble, biodegradable, translucent and colored or white granular powder (Maiti et al., 2012). It is a biggest volume synthetic resingenerated in a world which represented by a formula $\left(\mathrm{C}_{2} \mathrm{H}_{4} \mathrm{O}\right)_{\mathrm{n}}$ (Rowe et al., 2009). The PMMA is one of a most importantcommercial polymers which was known as Plexiglas and Lucite in America, Plexiglas and Perpex in Europe. The PMMA is a most important homo-polymer in a series of acrylics with adequate high temperature of glass transition (Sankar et al., 2004). Cellulose is a major component in the plant cell wall thus it forms the most abundant polymer on earth (Olatunji, 2015). Cellulose is a crystalline matter which insoluble in all organic solvents and infusible (Vroman and Tighzert, 2009). Starch is environmentally friendly material and is fully biodegradable. In addition a starch has low cost, nevertheless, because starch has comparatively poor mechanical properties compared to other petrochemical polymers and has high sensible towards a water, its use was limited (Vroman and Tighzert, 2009). Pure form of starch is tasteless, white and odorless powder. It is polysaccharide which consists from two types of a molecules, amylose and amylopectin (Olatunji, 2015).

Experimental procedure: Iraqi red beet is used after removing the leaves and cleaning, then cuts as slices and squeezes mechanically so concentrated juice is obtained in two states, the pure anthocyanin juice and its solid state obtained by evaporation the juice at $50^{\circ} \mathrm{C}$ then drying in vacuum oven at $50^{\circ} \mathrm{C}$ until obtained the pure solid anthocyanin.
The polymerization process of mechanically extracted anthocyanin is done by two ways as shown in Fig. 1:

- $\quad$ By boiling the juice at $102^{\circ} \mathrm{C}$ for 15 minute until deposit particles appeared then the deposit particles filtered and then dried in vacuum oven at $50^{\circ} \mathrm{C}$

- By heating the pure solid anthocyanin in oven at $110^{\circ} \mathrm{C}$ until a constant weight (weight loss is liberation of water by condensation polymerization)

Four types of biopolymers are used, synthetic biopolymers poly methyl methacrylate and polyvinyl alcohol and natural biopolymers starch and cellulose. They are different insamples preparation and their testing due to their differences in properties. Sample preparation is done on many steps and there are differences and similarities for each type of used biopolymers which depend onits blending portability with pigment. The samplepreparation steps are:

- $\quad$ Addition of pigment (pure solid anthocyanin and dimer anthocyanin by heating and boiling) to the biopolymers in the following percent ( 1 and 7\%)

- $\quad$ For mixing the pigment with biopolymers, ethanol was added, with a continuous stirring on a hot plate at $50^{\circ} \mathrm{C}$ until getting homogeneous material. Ethanol addition to mixture of PMMA with pigment lead to PMMA soluble and create stick materials

- Evaporating the solvent in vacuum oven at $50^{\circ} \mathrm{C}$

- The result is a colored polymeric material in solid form, but the result of PMMA blending was a hard solid material

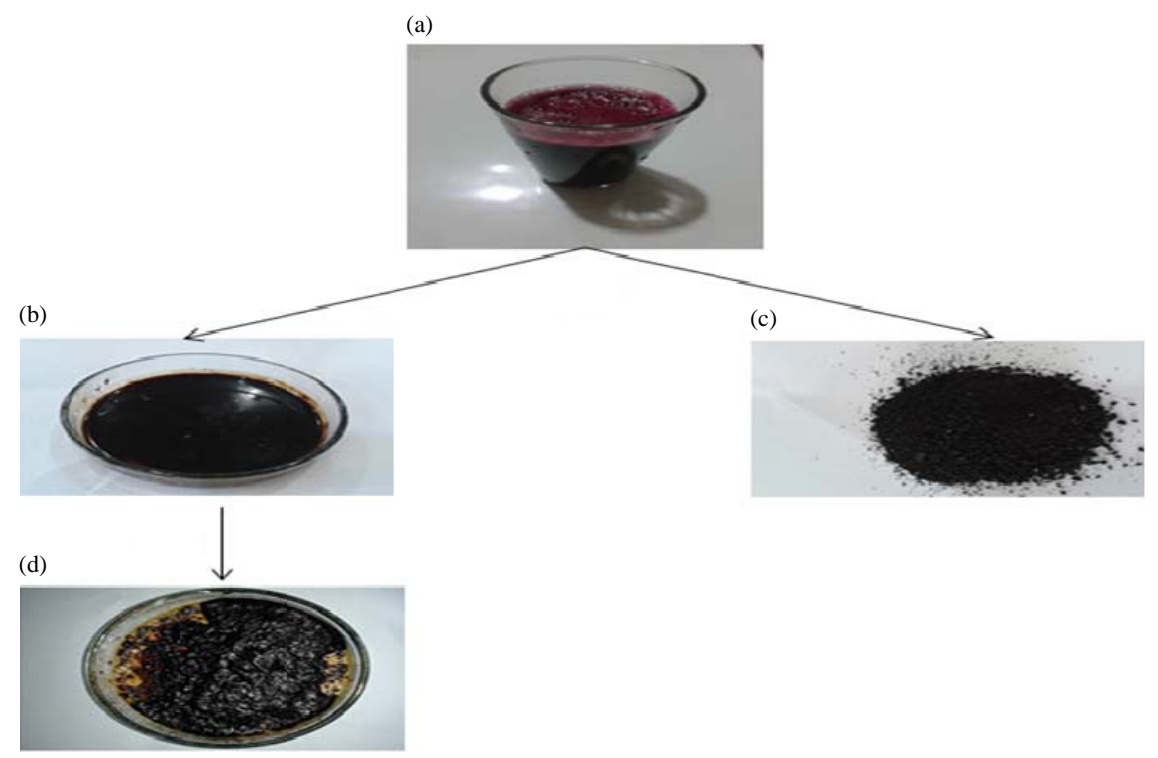

Fig. 1(a-d): (a) Pure anthocyanin juice, (b) Pure solid anthocyanin, (c) Dimer anthocyaninby boiling the juice at $102^{\circ} \mathrm{C}$ and (d) Dimer anthocyanin by heating the pure solid anthocyanin at $110^{\circ} \mathrm{C}$ 


\section{RESULTS AND DISCUSSION}

The water loss from heating3g of pure solid anthocyanin at $110^{\circ} \mathrm{C}$ until no change in weight (constant weight) was $0.5 \mathrm{~g}$. Figure 2 shows the general formula of anthocyanin.

$$
\text { Loss }=(0.5 / 3) \times 100=16.67 \%
$$

$\mathrm{Mw}=256 \mathrm{~g} / \mathrm{mol}$ (molecular weight of anthocyanin biomolecule)

Molecular weight of water molecule $=18 \mathrm{~g} \mathrm{~mol}^{-1}$

There are several probabilities of links in polymerization of anthocyanin biomolecule:

- One link between two anthocyanin molecules liberates one water molecule:

$$
\mathrm{X}=(3 \times 18) / 512 \rightarrow \mathrm{X}=10.55 \%
$$

- Two links between two anthocyanin molecules liberates two water molecules:

$$
\mathrm{X}=(3 \times 36) / 512 \rightarrow \mathrm{X}=21.09 \%
$$

- Two links between three anthocyanin molecules liberates two water molecules

$$
\mathrm{X}=(3 \times 36) / 768 \rightarrow \mathrm{X}=14.06 \%
$$

- Three links between two anthocyanin molecules liberates three water molecules

$$
X=(3 \times 54) / 512 \rightarrow X=31.64 \%
$$

- Three links between three anthocyanin molecules liberates three water molecules:

$$
X=(3 \times 54) / 768 \rightarrow X=21.09 \%
$$

- Three links between four anthocyanin molecules liberates three water molecules

$$
\mathrm{X}=(3 \times 54) / 1024 \rightarrow \mathrm{X}=15.82 \%
$$

where, $\mathrm{X}$ is water loss percent.

Conclusion from experimental and calculation results that is condensation polymerization occurs between two anthocyanin molecules by hydroxyl groups which agrees with the above probability item 2 shows $21.09 \%$ the closet to the actual $16.67 \%$ and the least steric effect as well as FTIR shows two new links are ether C-Oand ketone $\mathrm{C}=\mathrm{O}$ where ketone results from breaking the emerging ether linkage during polymerization process. Figure 3 shows the expected polymerization process between anthocyanin molecules:

$$
\mathrm{p}=\frac{100 \times 0.1667}{0.2109}
$$<smiles>OC1=Cc2c(O)cc(O)cc2OC1c1ccccc1</smiles>

Fig. 2: General formula of anthocyanin (Oancea and Oprean, 2011)<smiles>Oc1cc2c(O)c(c1)OC(c1ccccc1)C(Oc1cc(O)cc3c1OC(c1ccccc1)C(c1ccccc1)O3)=C2</smiles>

Fig. 3: Expected dimer formation

$$
\mathrm{p}=(100 \times 0.1667) / 0.2109
$$

$\mathrm{p}=79.04 \%$ (percent of anthocyanin in the juice).

From Fig. 4 noticed that the absorption spectrum of dimer anthocyanin (heating) is different from that of dimer anthocyanin (boiling) because the absorption is dependent on the polymerization process and film thickness of samples.

Figure 5 represents the FTIR spectrums of pure anthocyanin juice, pure solid anthocyanin, dimer anthocyanin (heating) and dimer anthocyanin (boiling). It is clear from the Table 1 that the absorption pattern of anthocyanin spectrums is matching to the standard.

From Fig. $5 \mathrm{~b}$ noticed that the absorption peaks of pure solid anthocyanin are similar to that of pure anthocyanin juice so it was not polymerized at $50^{\circ} \mathrm{C}$. There are new peaks arise after polymerization processes of anthocyanin where in case of dimer anthocyanin (heating) as shown in Fig. 5c there are two new peaksare ether $(\mathrm{C}-\mathrm{O})$ at $1325 \mathrm{~cm}^{-1}$ and ketone $(\mathrm{C}=\mathrm{O})$ at $1541.12 \mathrm{~cm}^{-1}$ where ketone results from breaking the emerging ether linkage during polymerization process. Appearance of the two new absorption bands at 1541.12 and $1325 \mathrm{~cm}^{-1}$ indicates that thereis dimer anthocyanin is formedby two linksand this supports the calculation results. In case of dimer anthocyanin (boiling) as in Fig. 5d also there are ether (C-O) at $1319.31 \mathrm{~cm}^{-1}$ and ketone $(\mathrm{C}=\mathrm{O})$ at $1558.48 \mathrm{~cm}^{-1}$ but new cyclic ether (C-O) at $1250 \mathrm{~cm}^{-1}$ arises because the molecules of anthocyanin in juice state are more free in motion and rotational so the polymerization process is more easer (three links between two anthocyanin molecules). 


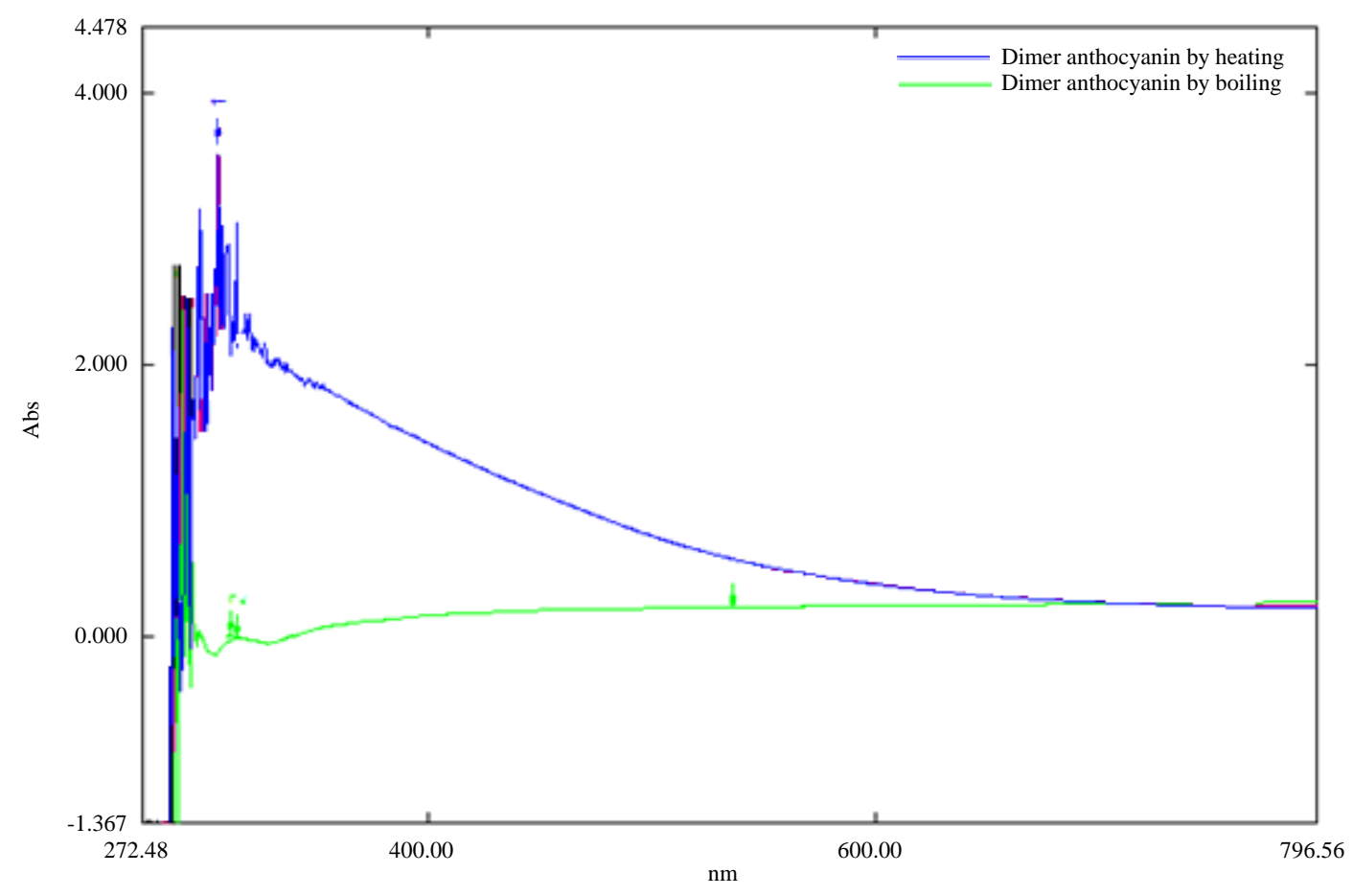

Fig. 4: Absorption spectra of dimeranthocyanin (by heating and boiling)

Table 1: Spectra $\left(\mathrm{cm}^{-1}\right)$ of pure anthocyanin juice

\begin{tabular}{lcc} 
Type of bond (Sankar et al., 2004$)$ & Experimental absorption peak $\left(\mathrm{cm}^{-1}\right)$ & Stander absorption peak $\left(\mathrm{cm}^{-1}\right)(\mathrm{Stuart}, 2004)$ \\
\hline Cyclic ether & 1051.20 & $1250-900$ \\
C-H bending & 1384.89 & 1380 \\
C C of benzene ring & 1627.92 & $1680-1600$ \\
C-H stretching & 2930.73 & 2930 \\
OH group & 3385.07 & $3920-3280$ \\
\hline
\end{tabular}

Figure 6 show the XRD results of pure solid anthocyanin, dimer anthocyanin (heating) and dimer anthocyanin (boiling).

From Fig. 6a noticed that the crystalline structure of pure solid anthocyanin is polycrystalline so the material with high crystalline especially at angles $(7.5,11.5,13,17,19,19.5,24.5$ and 25 . In case of dimer anthocyanin (heating), as in Fig. $6 \mathrm{~b}$ there is change in the crystalline structure where there is shifting to amorphous state and drooping in all crystallization values and there are new crystallization trends at angles $16,28,29.5,31.5$ and 40.5 which refer to changing in structure of dimer anthocyanin (heating). In Fig. 6c of dimer anthocyanin (boiling), there are new crystallization states at angles 14-15, 18-21, 31-32, 37-38.5, 40 and 43-44, which mean that, there is recrystallization happened in dimer anthocyanin (boiling) but also there is tendency to amorphous state. These differences in crystallization trends lead to changing in some physical properties such as color and this is happened really. A conclusion from XRD results that the crystalline structure of pure solid anthocyanin is quite different from that of dimer anthocyanin (by heating and boiling) and there is tendency to amorphous state in dimer anthocyanin (by heating and boiling). Can indicates that, the polymerization process was occurred but not all anthocyanin polymerized.

Figure 7 show the DSC analysis of pure poly methyl methacrylate and with $7 \%$ of pure solid anthocyanin, dimer anthocyanin (heating) and dimer anthocyanin (boiling).

The procedures from Eq. 1 will follow (Housecroft and Sharpe, 2005):

$$
\therefore \mathrm{E}_{\mathrm{a}}=\Delta \mathrm{H}^{\ddagger}+\mathrm{RT}
$$

Where:

$\mathrm{RT}=$ Thermal energy (work)

$\mathrm{pd}^{\prime} \mathrm{v}=\mathrm{RT}\left(\mathrm{kJ} \mathrm{mol}^{-1}\right)$ 
J. Eng. Applied Sci., 14 (Special Issue 6): 9455-9466, 2019
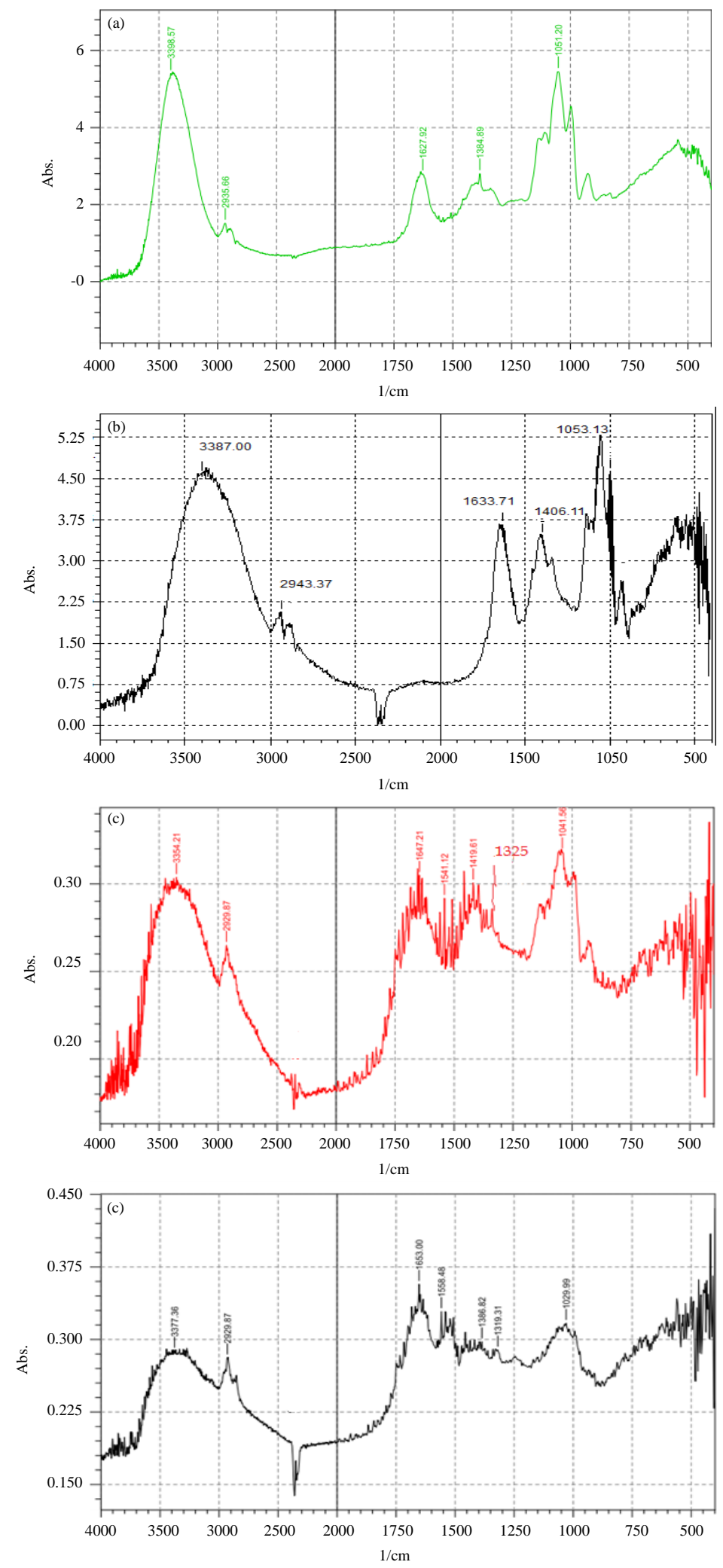

Fig. 5(a-d): FTIR spectrum of (a) Pure anthocyanin juice, (b) Pure solid anthocyanin, (c) Dimer anthocyanin (heating) and (d) Dimer anthocyanin (boiling) 

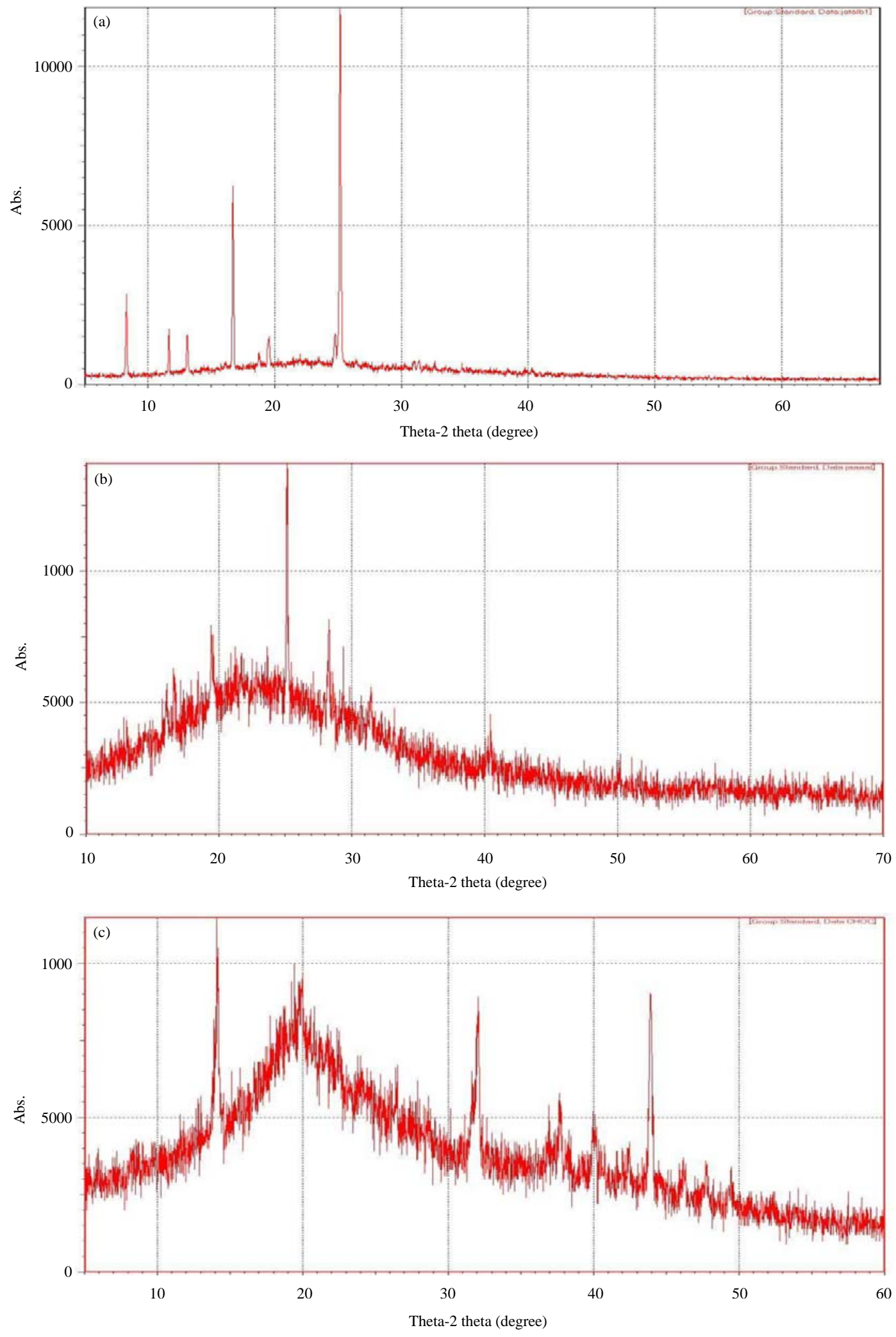

Fig. 6(a-c): XRD of (a) Pure solid anthocyanin, (b) Dimer anthocyanin (heating) and (c) Dimer anthocyanin (boiling) 
According to molecular models (an activation energy of chain rupture is about $60 \mathrm{kCal} \mathrm{mol}{ }^{-1}$ $\left(251 \mathrm{~kJ} \mathrm{~mol}^{-1}\right)$ so at room temperature the value of a decisive factor $\left(D_{f}\right)$ for chain rupture as a thermal fluctuation process is about 101 for 1 mole (Mohammed, 2012):

$$
\begin{aligned}
& \therefore \mathrm{E}_{\mathrm{a}}=\mathrm{H}^{\ddagger}+\mathrm{RT}=\mathrm{RTD}_{\mathrm{f}} \\
& \mathrm{E}_{\mathrm{a} \text { at R.T }}=251 \mathrm{~kJ} \mathrm{~mol}^{-1} \\
& \mathrm{E}_{\mathrm{a}}=\Delta \mathrm{H}^{\ddagger}+\mathrm{RT}=251
\end{aligned}
$$
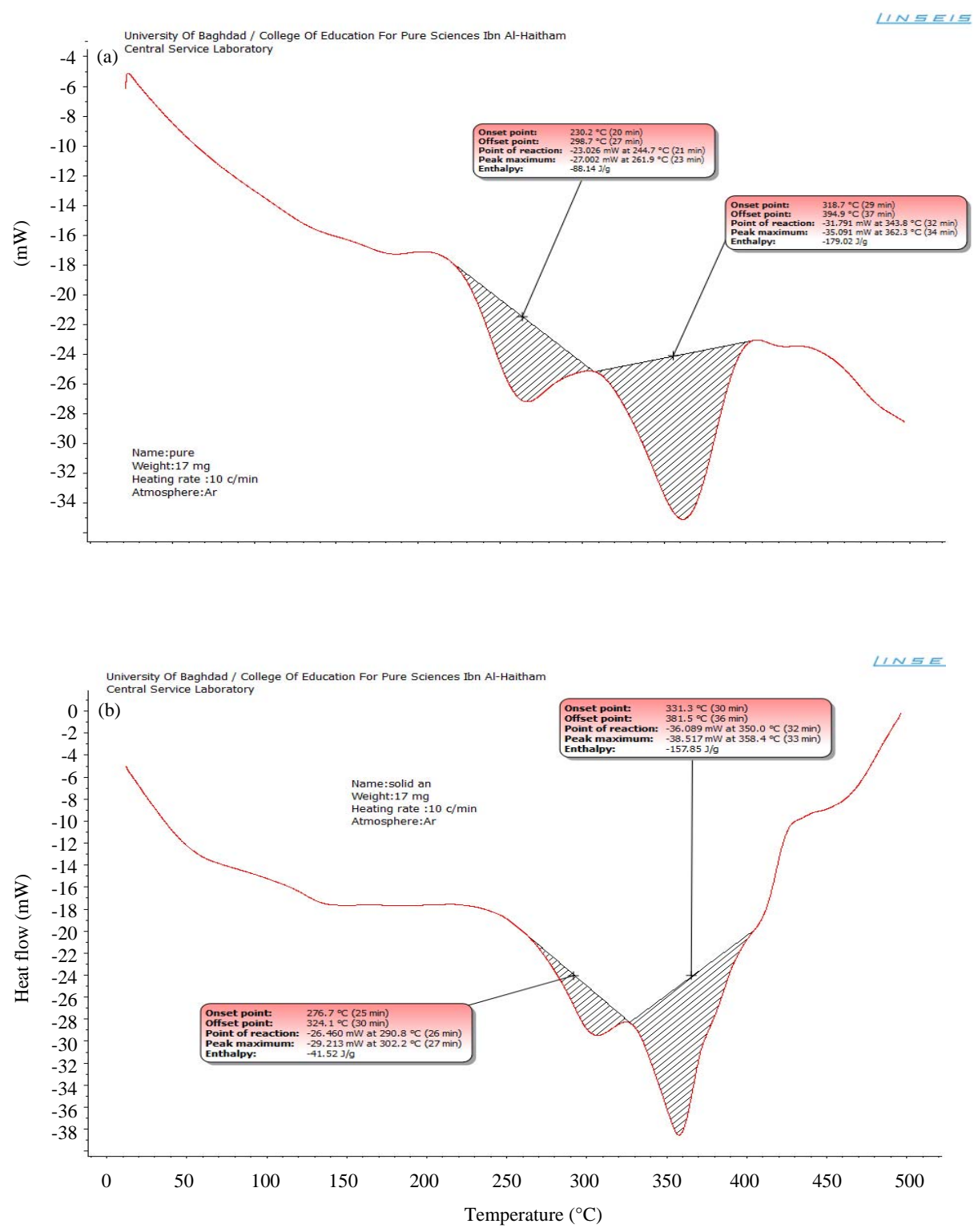

Fig. 7(a-d): Continue 

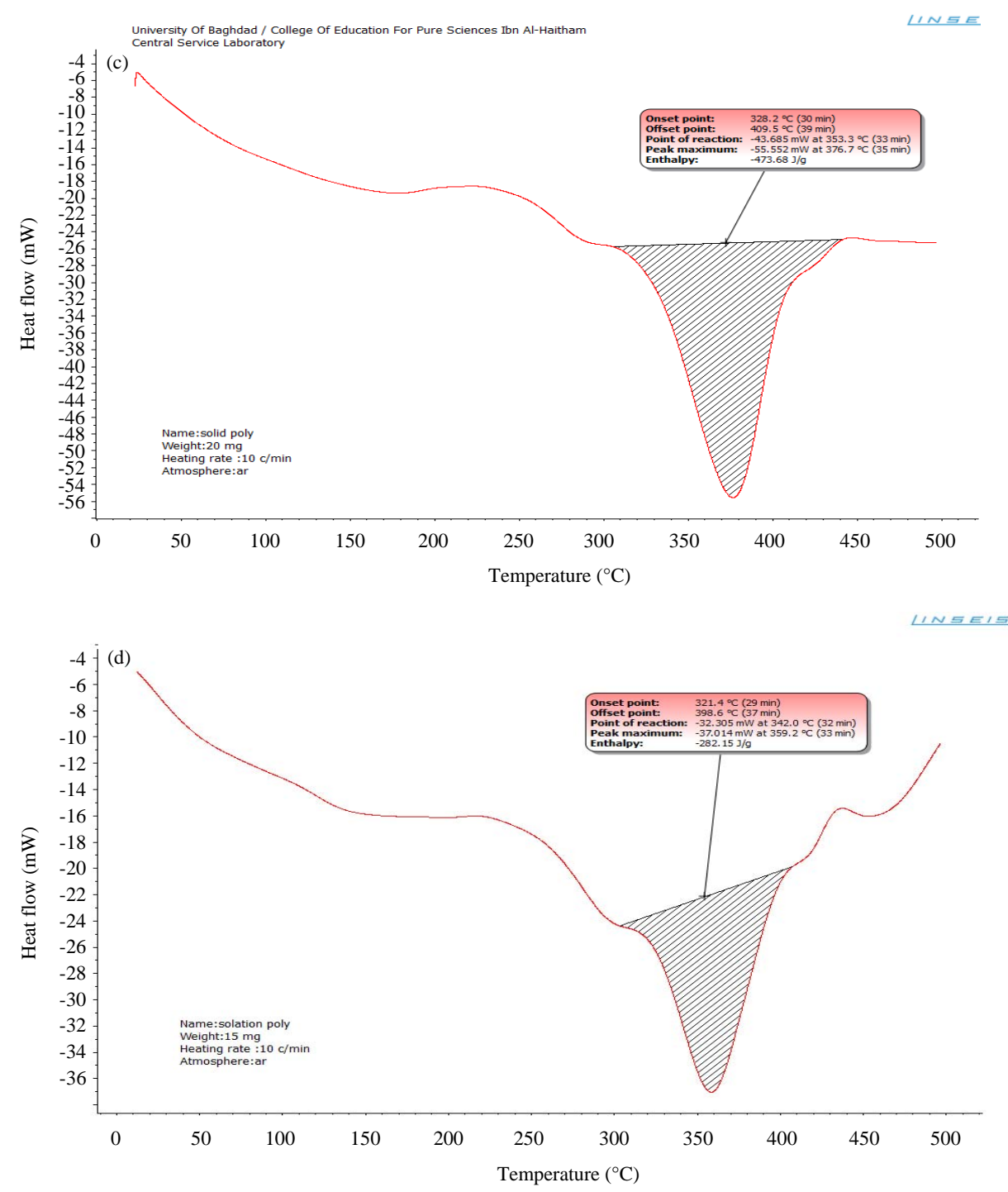

Fig. 7(a-d): DSC analysis of (a) Pure PMMA with (b) 7\% pure solid anthocyanin, (c) 7\% dimer anthocyanin (heating) and (d) $7 \%$ dimer anthocyanin (boiling)

\section{Poly Methyl Methacrylate Powder (PMMA):}

$$
\begin{gathered}
T_{\mathrm{g}} \text { of pure PMMA }=264.45^{\circ} \mathrm{C} \\
\mathrm{E}_{\mathrm{a}}=\mathrm{RTD}_{\mathrm{f}} \\
251=0.0083 \times 537.6 \times \mathrm{D}_{\mathrm{f}} \rightarrow \mathrm{D}_{\mathrm{f}}=56.25 \\
\Delta_{\text {df }}=\mathrm{D}_{\text {fat R.T }}-\mathrm{D}_{\text {fat } 264.45^{\circ} \mathrm{C}}=101.43-56.25=45.18
\end{gathered}
$$

Addition $\mathrm{E}_{\mathrm{a}}$ from different temp $\cdot_{\left(25 \& 264.45^{\circ} \mathrm{C}\right)}=\Delta \mathrm{D}_{\mathrm{f}} \times$ Each unit of $\mathrm{D}_{\mathrm{f}}(8)$

$$
\begin{gathered}
=45.18 \times 2.475=111.82 \mathrm{~kJ} \mathrm{~mol}^{-1} \\
\mathrm{E}_{\text {a at }\left(264.45^{\circ} \mathrm{C}\right)}=251-111.82=139.18 \mathrm{~kJ} \mathrm{~mol}^{-1} \\
\Delta \mathrm{T}=264.45-25=239.45^{\circ} \mathrm{C}
\end{gathered}
$$

$$
1^{\circ} \mathrm{C} \equiv \frac{\text { Addition } \mathrm{E}_{\mathrm{a}}}{\Delta \mathrm{T}} \equiv \frac{111.82}{239.45} \equiv 0.47 \mathrm{~kJ} \mathrm{~mol}^{-1}
$$

By addition 7\% pure solid Anthocyanin to PMMA: The temperature of chain rupture increases to 300.4 due to addition $7 \%$ pure solid anthocyanin.

$$
\begin{gathered}
\therefore \mathrm{T}_{\mathrm{g}}=300.4^{\circ} \mathrm{C} \\
\mathrm{E}_{\mathrm{a}}=\mathrm{RTD}_{\mathrm{f}} \\
251=0.0083 \times 573.55 \times \mathrm{D}_{\mathrm{f}} \rightarrow \mathrm{D}_{\mathrm{f}}=52.73 \\
\Delta \mathrm{T}=300.4-25=275.4^{\circ} \mathrm{C}
\end{gathered}
$$$$
\begin{aligned}
& \text { Addition } \mathrm{E}_{\mathrm{a}} \text { from different } \\
& \text { temp. }{ }_{\left(25 \& 300.4^{\circ} \mathrm{C}+7 \% \text { pure solid An. }\right)}
\end{aligned}=275.4^{\circ} \mathrm{C} \times 0.47 \mathrm{~kJ}^{\frac{\mathrm{mol}^{-1}}{{ }^{\circ} \mathrm{C}}}=129.44 \mathrm{~kJ} \mathrm{~mol}^{-1}
$$ 

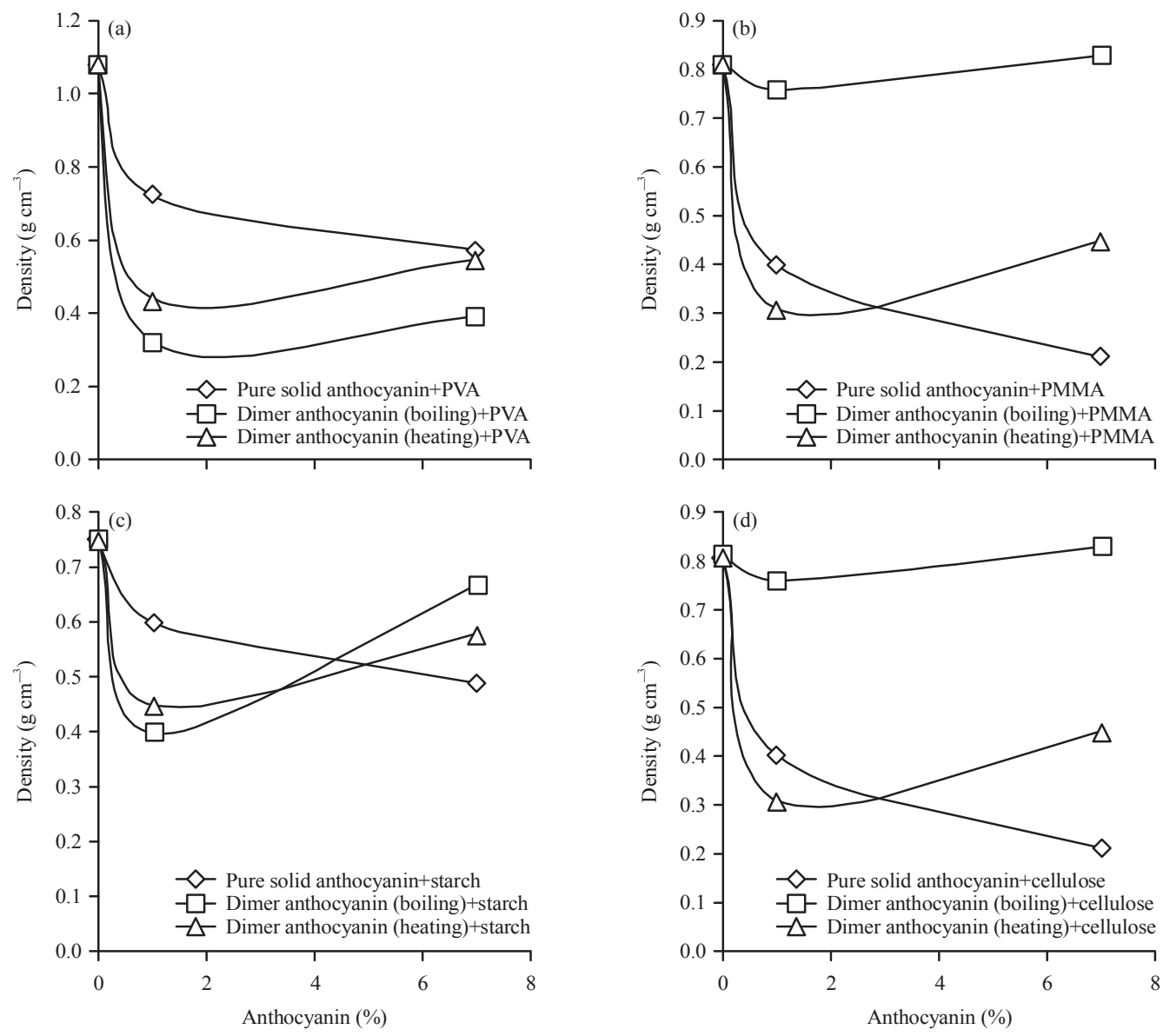

Fig. 8(a-d): Effect of pure solid anthocyanin, dimer anthocyanin (heating) and dimer anthocyanin (boiling) as increasing their percent on the density of (a) Polyvinyl alcohol, (b) Poly methyl methacrylate, (c) Starch and (d) Cellulose

Given energy by addition pigment $=111.82-129.44$

$=-17.62 \mathrm{~kJ} \mathrm{~mol}^{-1}$ (this given by $7 \%$ pure solid An.)

$$
\mathrm{E}_{\mathrm{a} \text { at }\left(300.4^{\circ} \mathrm{C}\right)}=139.18-(-17)=156.18 \mathrm{~kJ} \mathrm{~mol}^{-1}
$$

By addition 7\% dimer anthocyanin (heating) to PMMA: The temperature of chain rupture increases to 368.85 due to addition $7 \%$ dimer anthocyanin (heating).

$$
\begin{gathered}
\therefore \mathrm{T}_{\mathrm{g}}=368.85^{\circ} \mathrm{C} \\
\mathrm{E}_{\mathrm{a}}=\mathrm{RTD}_{\mathrm{f}} \\
251=0.0083 \times 642 \times \mathrm{D}_{\mathrm{f}} \rightarrow \mathrm{D}_{\mathrm{f}}=47.104 \\
\Delta \mathrm{T}=368.85-25=343.85^{\circ} \mathrm{C}
\end{gathered}
$$

$$
\begin{aligned}
& \text { Addition } \mathrm{E}_{\mathrm{a}} \text { from different } \\
& \text { temp. }{ }_{\left.\left(25 \& 368.85^{\circ} \mathrm{C}+7 \% \text { dimer An. (heating }\right)\right)}
\end{aligned}=343.85^{\circ} \mathrm{C} \times 0.47 \mathrm{~kJ}^{\circ} \frac{\mathrm{mol}^{-1}}{{ }^{\circ} \mathrm{C}}=161.61 \mathrm{~kJ} \mathrm{~mol}^{-1}
$$

Given energy by addition pigment $=111.82-161.61$

$$
\begin{gathered}
=-49.79 \mathrm{~kJ} \mathrm{~mol}^{-1} \text { (this given by } 7 \% \text { dimer An. (heating)) } \\
\mathrm{E}_{\mathrm{a} \text { at }\left(368.85^{\circ} \mathrm{C}\right)}=139.18-(-49.79)=188.97 \mathrm{~kJ} \mathrm{~mol}^{-1}
\end{gathered}
$$

By addition 7\% dimer Anthocyanin (boiling) to PMMA: The temperature of chain rupture increases to 360 due to addition 7\% dimer anthocyanin (boiling).

$$
\begin{gathered}
\therefore \mathrm{T}_{\mathrm{g}}=360^{\circ} \mathrm{C} \\
\mathrm{E}_{\mathrm{a}}=\mathrm{RTD}_{\mathrm{f}} \\
251=0.0083 \times 633.15 \times \mathrm{D}_{\mathrm{f}} \rightarrow \mathrm{D}_{\mathrm{f}}=47.76 \\
\Delta \mathrm{T}=360-25=335^{\circ} \mathrm{C}
\end{gathered}
$$

Noticed that the glass transition temperature and activation energy of poly methyl methacrylate (PMMA) increase after addition of anthocyanin pigment which due to H-bonding formation between PMMA and pigment (Table 2).

From Fig. 8 noticed that density of biopolymers decreases as increasing percent of pure solid anthocyanin 

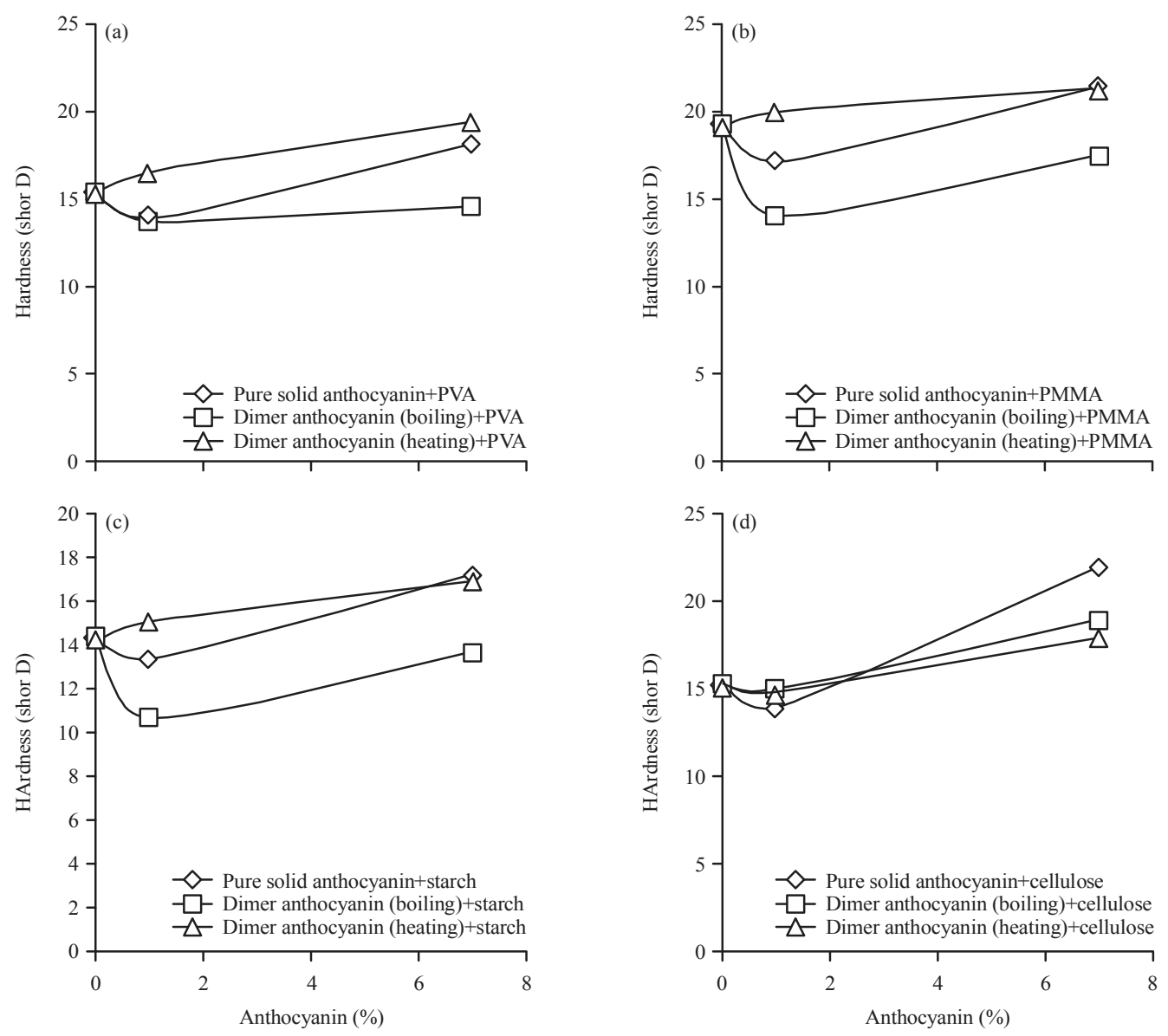

Fig. 9(a-d): Effect of pure solid anthocyanin and dimer anthocyanin (by heating and boiling) on the hardness of (a) Polyvinyl alcohol, (b) Poly methyl methacrylate, (c) Starch and (d) Cellulose

Table 2: Effect of natural pigment on PMMA at R.T $\left(25^{\circ} \mathrm{C}\right)$ and $\mathrm{E}_{\mathrm{a}}\left(251 \mathrm{~kJ} \mathrm{~mol}^{-1}\right)$ with $\mathrm{D}_{\mathrm{f}}(101.43)$

\begin{tabular}{lccccc}
\hline Substance & $\mathrm{T}_{\mathrm{g}}\left({ }^{\circ} \mathrm{C}\right)$ & $\mathrm{D}_{\mathrm{f}}$ & $\begin{array}{c}\mathrm{E}_{\mathrm{a}} \text { at } \mathrm{T}_{\mathrm{g}} \\
\left(\mathrm{kJ} \mathrm{mol}^{-1}\right)\end{array}$ & $\begin{array}{c}\text { Addition } \mathrm{E}_{\mathrm{a}} \\
\left(\mathrm{kJ} \mathrm{mol}^{-1}\right)\end{array}$ & $\begin{array}{c}\text { Given energy by addition } \\
\left.\text { pigment }(\mathrm{kJ} \mathrm{mol})^{-1}\right)\end{array}$ \\
\hline Pure PMMA & 264.45 & 56.250 & 139.18 & 111.82 & - \\
7\% pure solid anthocyanin & 300.40 & 52.730 & 156.18 & 129.44 & -17.62 \\
7\% dimer An. (heating) & 368.85 & 47.104 & 188.97 & 161.61 & -49.79 \\
7\% dimer An. (boiling) & 3600 & 47.760 & 184.81 & 157.45 & -45.63 \\
\hline
\end{tabular}

due to the presence of exchangeable proton which reacts with functional groups in biopolymers and destroys the lattice structure of biopolymers, but in case of the blends composed from biopolymers and dimer anthocyanin (by heating and boiling), the diffusion of dimer anthocyanin is take placing through the biopolymers which makes vacancies thus the densities decrease. As the dimer anthocyanin percent increase the vacancies full with the exceed dimer anthocyanin and so the interaction with the biopolymers increased thus the densities increase.

$$
\begin{aligned}
& \text { Addition } \mathrm{E}_{\mathrm{a}} \text { from different } \\
& \text { temp. }{ }_{\left(25 \& 335^{\circ} \mathrm{C}+7 \% \text { dimer An. (boiling) }\right)}
\end{aligned}=335^{\circ} \mathrm{C} \times 0.47 \mathrm{~kJ} \frac{\mathrm{mol}^{-1}}{{ }^{\circ} \mathrm{C}}=157.45 \mathrm{~kJ} \mathrm{~mol}^{-1}
$$

Given energy by addition pigment $=111.82-157.45$

$$
\begin{gathered}
=-45.63 \mathrm{~kJ} \mathrm{~mol}^{-1} \text { (this given by } 7 \% \text { dimer An. (boiling)) } \\
\mathrm{E}_{\text {a at }\left(360^{\circ} \mathrm{C}\right)}=139.18-(-45.63)=184.81 \mathrm{~kJ} \mathrm{~mol}^{-1}
\end{gathered}
$$

As shown in Fig. 9 the hardness values of biopolymers rises as increasing percent of pure solid anthocyanin and dimer anthocyanin (by heating and boiling) due to the interaction between hydroxyl groups in anthocyanin and functional groups in biopolymers where strong bonding is formed, so the added anthocyanin acts as filler and binder material leads to reduce the ability of a molecule in biopolymers to slide on each other's and then rises the hardness degree. 


\section{CONCLUSION}

It seems that the highest percent of the red pigment (anthocyanin) in red beet juice is $\approx 79 \%$. Boiling of the red beet juice results in dimerization which results in losing the exchangeable proton activity. Polymerization by boiling the juice at $102^{\circ} \mathrm{C}$ or by heating the solid anthocyanin at $110^{\circ} \mathrm{C}$ results in dimer anthocyanin. Slightly solubility of dimer anthocyanin pigmentin water, acetone and ethanol. Glass transition temperature $\left(\mathrm{T}_{\mathrm{g}}\right)$ of poly methyl methacrylate (PMMA) increases upon addition of pure solid anthocyanin and dimer anthocyanin (by heating and boiling) due to H-bonding formation. Activation energy of poly methyl methacrylate (PMMA) also increases after addition of anthocyanin pigment. Density of biopolymers decreases uponaddition of pure solid anthocyanin and dimer anthocyanin (by heating and boiling). Hardness of biopolymers increases with increasing percent of both pure solid anthocyanin and dimer anthocyanin (by heating and boiling).

\section{ACKNOWLEDGMENTS}

First of all I thank Allah who gave me ability and desire to complete this work. I would like to express my deep appreciation and sincere thanks to Professor Jaleel K. Ahmed and Professor Zuhair J. Abdul Ameer for their active valuable supervision; sincere. Thanks are also expressed to the staff of the Material Engineering College specially in Polymers and Petrochemical Industries laboratories for the encouragement during this study. Finally, I would like to thank my family, my friends and everyone help me to accomplish the present work.

\section{REFERENCES}

Alongi, K., 2010. Effects of concentration prior to cold-stabilization on the color of concord grape juice. Master's Thesis, Cornell University, Ithaca, New York, USA.

Billmeyer, F.W., 1984. Textbook of Polymer Science. 3rd Edn., John Wiley \& Sons, Hoboken, New Jersey, USA., ISBN:9789971511418, Pages: 578.

Bower, D.I., 2002. An Introduction to Polymer Physics. 1st Edn., Cambridge University Press, New York, ISBN-13: 978-0521637213, Pages: 468.

Clemente, E. and D. Galli, 2011. Stability of the anthocyanins extracted from residues of the wine industry. Food Sci. Technol., 31: 765-768.
Ferreiro-González, M., C. Carrera, A. Ruiz-Rodríguez, G.F. Barbero, J. Ayuso, M. Palma and C.G. Barroso, 2014. A new solid phase extraction for the determination of anthocyanins in grapes. Mol., 19: 21398-21410.

Fried, J.R., 2014. Polymer Science and Technology. 3rd Edn., Prentice Hall, New Jersey, USA., ISBN: 9780137039937, Pages: 688.

Housecroft, C.E. and A.G. Sharpe, 2005. Inorganic Chemistry. 2nd Edn., Pearson Education Limited, UK., ISBN: 9780130399137 , Pages: 949.

Maiti, J., N. Kakati, S.H. Lee, S.H. Jee, B. Viswanathan and Y.S. Yoon, 2012. Where do poly(vinyl alcohol) based membranes stand in relation to Nafion ${ }^{\circledR}$ for direct methanol fuel cell applications? J. Power Sources, 216: 48-66.

Mei, X., H. Qin, J. Wang, G. Wang, C. Liu and Y. Cai, 2014. Studies on physicochemical characteristics of anthocyanin from super dark maize. J. Food Nutr. Res., 2: 109-114.

Miraje, S.Y., N.M. Amlepatil, A.K. Sahoo and G.V. Mote, 2015. Anthocyanin extraction from winery waste material: A review. J. Innovations Pharm. Biol. Sci., 2: 218-221.

Mitchell, B.S., 2004. An Introduction to Materials Engineering and Science for Chemical and Materials Engineers. John Wiley and Sons, Hoboken, New Jersey, USA., Pages: 961.

Mohammed, M.J., 2012. Effect of natural pigments on the polymer secondary bonds. Master's Thesis, College of Materials Engineering, University of Babylon, Hillah, Iraq.

Oancea, S. and L. Oprean, 2011. Anthocyanins, from biosynthesis in plants to human health benefits-A review. Acta Univ. Cibiniensis Ser. E: Food Technol., 15: 3-16.

Odian, G., 2004. Principles of Polymerization. 4th Edn., John Wiley and Sons Inc., Hoboken, New Jersey, ISBN-13: 978-0471274001, Pages: 832 .

Olatunji, O., 2015. Natural Polymers: Industry Techniques and Applications. Springer, Berlin, Germany, ISBN: 9783319264141, Pages: 369.

Palencia, L.A.P., 2009. Chemical characterization, bioactive properties and pigment stability of polyphenolics in Acai (Euterpe oleracea Mart.). Ph.D. Thesis, Texas A\&M University-Kingsville, Kingsville, Texas, USA.

Predrag, V., B. Branka, J. Miodrag and M. Snezana, 2003. [Change of anthocyanins content during raspberry extraction]. J. Agric. Sci., 48: 85-102, (In Serbian). 
Rowe, R.C., P.J. Sheskey and M.E. Quinn, 2009. Handbook of Pharmaceutical Excipients. 6th Edn., Pharmaceutical Press, London, ISBN: 9780853697923 , Pages: 888.

Sankar, V., T.S. Kumar and K.P. Rao, 2004. Preparation, characterisation and fabrication of intraocular lens from photo initiated polymerised poly (Methyl methacrylate). Trends Biomater. Artif. Organs., 17: 24-30.
Stuart, B., 2004. Infrared Spectroscopy: Fundamentals and Applications. John Wiley \& Sons, Hoboken, New Jersey, USA., ISBN: 9780470011133, Pages: 242.

Tsanova-Savova, S., S. Dimov and F. Ribarova, 2002. Anthocyanins and color variables of Bulgarian aged red wines. J. Food Compos. Anal., 15: 647-654.

Vroman, I. and L. Tighzert, 2009. Biodegradable polymers. Materials, 2: 307-344. 